\title{
THE RELATIONSHIP BETWEEN INNOVATION CULTURE AND INNOVATION PERFORMANCE
}

Eirikur Hilmarsson, School of Business, University of Iceland, Reykjavik, Iceland Gunnar Oskarsson, School of Business, University of Iceland, Reykjavik, Iceland Thorhallur Gudlaugsson, School of Business, University of Iceland, Reykjavik, Iceland

dx.doi.org/10.18374/IJBR-14-1.8

\begin{abstract}
Innovation has mainly been associated with new product development and creation of new processes. This view has been changing, and now innovation can be related to any part of the value chain, whether developing new services, new business models, rethinking cooperation, revenue streams, distribution channels, or management styles. This new view of innovation applies to retailing as well as industry or service. It is, therefore, of increasing interest to gain a deeper insight into factors that have an impact on innovation performance. This research deals with two questions: "Is there a relationship between innovation culture and performance in innovation?" and "Is there a relationship between innovation culture and the front and back end of innovation performance?" The methodology is quantitative, in the form of a survey. The population of interest was firms in Iceland with more than 50 employees in manufacturing, retail and services. A total of 265 managers where contacted and the response rate was $74 \%$. The findings show a strong relationship between innovation culture and innovation performance $(r=0.56)$, which is the answer to question one and in line with earlier findings. A strong relationship is noted between innovation culture and the front end of innovation ( $r=0.68)$, and innovation culture and the back end of innovation $(r=0.48)$, which is the answer to question two.
\end{abstract}

Keywords: Innovation, Innovation culture, Innovation performance, Front end of innovation 